LAS POLÍTICAS PÚBLICAS DE PROTECCIÓN INFANTIL: ADECUACIÓN AL INTERÉS SUPERIOR DEL NIÑO

\title{
LAS POLÍTICAS PÚBLICAS DE PROTECCIÓN INFANTIL: ADECUACIÓN AL INTERÉS SUPERIOR DEL NIÑO
}

\section{PUBLIC POLICIES FOR CHILD PROTECTION: ADEQUACY TO THE BEST INTEREST OF THE CHILD}

Zuleima del Carmen López Muñoz*

* Maestra en Estudios Jurídicos. División Académica de Ciencias Sociales y Humanidades de la Universidad Juárez Autónoma de Tabasco.

Dirección para recibir correspondencia: zulei_lomu@hotmail.com 
LAS POLÍTICAS PÚBLICAS DE PROTECCIÓN INFANTIL: ADECUACIÓN AL INTERÉS SUPERIOR DEL NIÑO

\section{RESUMEN}

Desde disciplinas diversas y con enfoques variados, el estudio de las políticas públicas de protección infantil ha sido constante desde hace décadas y sin asociarse con exclusividad a la acción gubernamental, sino además a otras disciplinas como la administración pública, la sociología, la ciencia política y la sociología política; sin embargo, el debate abierto a las doctrinas proteccionistas de la infancia han dado lugar a un desafío aún más complejo que consiste en reconocer que estos son titulares de derecho.

OBJETIVO: Analizar a través de elementos teóricos y doctrinales la naturaleza y función del principio del interés superior del niño para entender los cambios paradigmáticos en cuanto al reconocimiento de los menores a partir del panorama internacional y la reforma constitucional en materia de derechos humanos.

MATERIAL Y MÉTODO: Básicamente es el de doctrina analítica, manejado para la determinación de los elementos del objeto de estudio, desarrollando los conceptos en forma principal de población infantil y políticas públicas; utilizando además el método de sociología jurídica orientado al enfoque y proceso de las políticas públicas infantiles.

RESULTADOS: Se determina que el interés superior del menor es una cláusula dinámica de aplicación para todas las instituciones cuya labor y decisiones repercuten en los niños y la efectividad de sus derechos; por lo tanto, una política pública no consiste únicamente en procedimientos y actores pues además conlleva una afirmación de valores públicos o principios insalvables, que fundamentan (función justificativa) y guían (función directiva) todas las medidas adoptadas por el Estado, las cuales incluyen no solo las decisiones, sino también todos los actos, conductas, propuestas, servicios, procedimientos y demás iniciativas.

CONCLUSIONES: Una política pública no surge ni puede evolucionar de manera aislada, pues supone una capacidad de adaptación y compromiso con un sistema de valores específicos o ideologías definidas, no como un código moral o un proyecto político de sociedad, sino como la necesidad de incorporar los principios al análisis de las políticas públicas en respuesta concreta a problemas concretos que requieren la intervención del Estado.

PALABRAS CLAVE: Políticas públicas. Interés superior del menor. Principio rector. Derechos del niño. 
LAS POLÍTICAS PÚBLICAS DE PROTECCIÓN INFANTIL: ADECUACIÓN AL INTERÉS SUPERIOR DEL NIÑO

\section{ABSTRACT}

From diverse disciplines and a varied of approaches, the study of public policies of child protection has been constant for decades and without being associated exclusively to governmental action, but also to other disciplines such as public administration, sociology, political science and political sociology; However, the open debate on the protectionist doctrines of childhood has given rise to an even more complex challenge, which consists in recognizing that they are entitled to law.

OBJECTIVE: To analyze, through theoretical and doctrinal elements, the nature and function of the principle of the child's best interest to understand the paradigmatic changes regarding the recognition of minors from the international panorama and the constitutional reform in the matter of human rights.

MATERIAL AND METHOD: Basically it is the one of analytical doctrine, used to determine the elements of the object of this study, developing concepts mainly of child population and public policies; also using the method of legal sociology oriented to the approach and process of public policies for children.

RESULTS: It is determined that the child's best interest is a dynamic clause applicable to all institutions whose work and decisions affect children and the effectiveness of their rights; Therefore, a public policy not only consist of procedures and actors, but also it also implies an assertion of public values or insurmountable principles, which support (justifying function) and guide (directive function) all the measures adopted by the State, which include not only the decisions, but also all the acts, behaviors, proposals, services, procedures and other initiatives

CONCLUSIONS: A public policy does not arise nor can it evolve in isolation, since it implies a capacity for adaptation and commitment to a system of specific values or defined ideologies, not as a moral code or a political project of society, but as the need to incorporate the principles to the analysis of the public policies in concrete answer to concrete problems that require the intervention of the State

KEY WORDS: Public Policies. The Child's Best Interest. Guiding principle. Children's rights. 
LAS POLÍTICAS PÚBLICAS DE PROTECCIÓN INFANTIL: ADECUACIÓN AL INTERÉS SUPERIOR DEL NIÑO

\section{INTRODUCCIÓN}

En materia de protección y reconocimiento de los derechos de los menores, resulta necesario el fomento de ellos, los cuales ya a nivel internacional, dichos menores han sido reconocidos en aquiescencia como titulares de derechos humanos, dicha titularidad no solo comprende su ejercicio sino también prevé a su vez situaciones de desprotección o desconocimiento de ellos, que se traducen en actos que vulneran sus derechos y defensa de estos.

En consecuencia, es significativo indicar que este estudio se inicia desde la perspectiva de la cultura de los derechos humanos, pues al estar introducidos en instrumentos jurídicos internacionales se muestran como una serie de compromisos que deben ser asumidos por parte del legislador, magistrados, jueces, las autoridades administrativas, los organismos gubernamentales y la sociedad civil del estado parte, con el único fin de proteger el goce y disfrute de los derechos de los menores en todas sus vertientes sociales.

Resulta importante el recuento de la evolución jurídica del sistema mexicano en materia de derechos humanos, la cual a partir del 10 de junio del 2011 aporta una elevación al rango constitucional de los derechos humanos comprendidos en los tratados internacionales, lo que extiende su reconocimiento inclusive como parte de la obligación del Estado, quien se encuentra compelido a la implementación de políticas públicas conforme a los esquemas no solo señalados por la constitución, pues además a los internacionales; se acierta la noción en la que todas las personas, incluyendo los niños, son titulares de derechos, lo que marca un cambio sustancial en la protección jurídica, la cual para los niños, niñas y adolescentes se reviste de la particularidad de ser especial o bien una supraprotección.

Si bien, una base fundamental de dicha protección especial está a cargo de la función legislativa y jurisdiccional, es también una función dentro del ámbito administrativo; es decir, de los servidores públicos en general, encargados de elaborar las políticas de desarrollo social.

Sin lugar a dudas, las niñas, niños y adolescentes, han sido determinados como sujetos en estado de vulnerabilidad, caracterizándose por tener debilidad, desventaja o problema para el desempeño y la movilidad social, se ha señalado que por diversas razones, se consideran en condiciones de indefensión particularmente agudas y que, por lo tanto, requieren un trato especial de las políticas públicas (Dueñas, 2016, pp.1-2). 
LAS POLÍTICAS PÚBLICAS DE PROTECCIÓN INFANTIL: ADECUACIÓN AL INTERÉS SUPERIOR DEL NIÑO

\section{Acerca de las políticas públicas}

Es evidente que en el campo de las políticas públicas su desarrollo teórico supone un número considerable de nociones y definiciones al respecto; sin embargo, nos remite a reconocer como punto en común su naturaleza que conlleva aspectos económicos, administrativos, políticos y hasta culturales. Louis Valentín Mballa (2017) propone la siguiente definición:

Políticas públicas como el conjunto de decisiones y acciones racionales del gobierno para dar solución bajo una normativa definida, a diversos problemas públicos suscitados por las necesidades de las personas. Esto significa que una política pública emana de una decisión del gobierno con la finalidad de atender y solucionar un problema público específico (p.35).

Desde esta perspectiva general, aquella persona o grupo social vinculado a un problema colectivo son indicados para una intervención pública a través de una política; es decir, no pueden estar independizadas de lo público o del interés común.

Al enfatizar la dimensión de interés público, destaca que se integra de una protección dirigida a un sector de la población, el cual está frente a un posible riesgo o perjuicio que ha sido detectado con anterioridad, de manera que no pueden ser modificados con espontaneidad.

En palabras de Franco Corzo (2017), las políticas públicas, son acciones de gobierno con objetivos de interés público que surgen de decisiones sustentadas en un proceso de diagnóstico y análisis de factibilidad, para la atención efectiva de problemas públicos específicos, en donde participa la ciudadanía en la definición de problemas y soluciones (p. 84).

Resulta interesante su definición ya que contempla su origen en un conjunto o procesamiento de fases u operaciones sucesivas para elaborarla, además que no se realza el ejercicio del poder a través de las instituciones, en vista de que requieren la participación de los particulares u otros actores, tan es así que no solamente se remite a las decisiones, acciones o inacciones de las autoridades, sino que intrínsecamente en ellas se dan decisiones consensuadas con la ciudadanía.

Además de estos elementos antes referidos, precisa la eventualidad de una situación definida como problemática la cual está generando demanda y está localizada en un ambiente determinado, ya sea para nutrirlo, modificarlo o mantenerlo, visto que una política pública no se LÓPEZ-MUÑOZ Z. DEL C. 
LAS POLÍTICAS PÚBLICAS DE PROTECCIÓN INFANTIL: ADECUACIÓN AL INTERÉS SUPERIOR DEL NIÑO

realiza involuntariamente como una respuesta instintiva, sino debe existir un objetivo bien planificado en ella.

En este sentido Merino y Cejudo (2010), en la introducción de su libro Problemas, decisiones y soluciones. Enfoques de política pública, comentan que el análisis de políticas públicas esta invariablemente ligado a la solución de un problema público (p. 5).

"Todos los análisis de políticas públicas comparten la misma idea central de que su objeto de estudio estriba en la definición y en la búsqueda de soluciones a los problemas públicos. El análisis de políticas públicas tiene sentido si, y sólo si, el resultado de sus investigaciones apunta hacia la solución de los problemas públicos" (Franco Corzo, 2017, p. 91).

Por otra parte, al hablar de la formulación de las políticas públicas con perspectiva de derechos humanos, temática que ha adquirido mucha preeminencia en los últimos años, es un valor agregado que genera un desafío más, originado a partir de la Declaración y Programa de Acción de Viena de 1993, donde se recomendó que los Estados debieran crear programas de derechos humanos.

Esta temática de los derechos humanos "se vincula con los tópicos de las políticas públicas en la medida que este constituye el referente y fin último de las mismas, y estas últimas a su vez se convierten en el instrumento idóneo para su realización" (Sandoval, 2011, p.110); es decir, que aquellas políticas públicas con enfoque de derechos humanos están basadas en las obligaciones y principios establecidos en los diversos instrumentos en materia de derechos humanos, de los cuales el Estado ha formado parte voluntariamente.

En efecto, si lo que se quiere alcanzar es el fortalecimiento del bienestar social de la infancia, bajo la perspectiva de derechos, es necesario el reconocimiento explícito que le ha dado el marco jurídico internacional de los derechos humanos con sus criterios y principios.

En el caso de México, en el contexto de profundización y expansión de los derechos humanos, a través del Decreto que modifica la denominación del Capítulo I del Título Primero y reforma diversos artículos de la Constitución Política de los Estados Unidos Mexicanos, publicado en el Diario Oficial de la Federación el 10 de junio de 2011, el artículo $1^{\circ}$ y la inclusión del principio pro persona, eleva a rango constitucional los criterios de: universalidad, interdependencia, indivisibilidad y progresividad que caracterizan a los derechos humanos. 
LAS POLÍTICAS PÚBLICAS DE PROTECCIÓN INFANTIL: ADECUACIÓN AL INTERÉS SUPERIOR DEL NIÑO

Bien puede sostenerse, que deben existir aspectos mínimos que deben considerarse en la elaboración de una política pública orientada por el enfoque, y esos aspectos mínimos son los que responden a una problemática colectiva que requiere atención particular, considerando los diversos resultados o matices en la medida en que las distintas situaciones lo ameriten.

\section{Los derechos humanos del niño a partir de las naciones unidas, como marco para la construcción de políticas públicas}

"La nueva concepción concentrada en el interés superior de los niños, niñas y adolescentes tuvo sus orígenes en el sistema anglosajón, específicamente en la Child Welfare and adopción Asistanse Act de 1980 de los Estados Unidos de América y se vio reflejada de manera primordial en la Convención sobre los Derechos de los niños y niñas de las Naciones Unidas de 1989" (López-Contreras, 2015, p. 56), la cual es el instrumento internacional y convencional que materializa la concreción normativa de protección del menor.

La Convención sobre los Derechos del Niño (1989) advierte en su artículo 3, párrafo 1, de manera definida el interés superior del niño hacia las políticas públicas como una norma fundamental que será tomada en cuenta por cualquier autoridad de cualquier nivel, lo que implica una evolución del derecho de la infancia, en cuanto a su protección y satisfacción, la cual no puede ser restringida por intereses utilitaristas.

En todas las medidas concernientes a los niños que tomen las instituciones públicas o privadas de bienestar social, los tribunales, las autoridades administrativas o los órganos legislativos, una consideración primordial a que se atenderá será el interés superior del niño (Art. 3.1).

Tal como lo señala el Comité de los Derechos del Niño, en su observación general número 14 (2013): "El objetivo del artículo 3, párrafo 1, es velar porque el derecho se observe en todas las decisiones y medidas relacionadas con el niño. Esto significa que, en cualquier medida que tenga que ver con uno o varios niños, su interés superior deberá ser una consideración primordial a que se atenderá. El término "medida" incluye no solo las decisiones, sino también todos los actos, conductas, propuestas, servicios, procedimientos y demás iniciativas (Comité de los Derechos del niño, 2013, párr. 17).

Implicando de este modo, jurídica y socialmente, al interés superior del menor, como elemento rector al cual han de ceñirse las acciones de los Estados a través de sus autoridades e incluso 
LAS POLÍTICAS PÚBLICAS DE PROTECCIÓN INFANTIL: ADECUACIÓN AL INTERÉS SUPERIOR DEL NIÑO

las instituciones privadas y la sociedad, en lo que concierne a la protección especial de la infancia, de ahí que sea señalado por el Comité de los derechos del niño, instituido por la propia Convención como uno de sus principios generales que la orienta y la conduce, es sustancial reconocer que el interés superior del menor, es polifacético ya que es ilimitado al emplearse 0 servirse para resolver o determinar la situación al niño o niña en todas sus esferas sociales.

Así también, el Comité de los Derechos del Niño, en su observación general numero 14 (2013), señala sobre el derecho del niño a que su interés superior sea una consideración primordial, en la que dicho interés es un concepto triple: un derecho sustantivo, un principio jurídico interpretativo fundamental y una norma de procedimiento, aunque en definitiva sigue siendo un concepto dinámico que abarca diversos temas en constante evolución (Comité de los Derechos del niño, 2013, párr.11); el objetivo principal de este trabajo, responde a una contribución de los variados debates hermenéuticos sobre este concepto, proyectado de manera concreta en el ordenamiento jurídico hacia las políticas públicas.

Cabe señalar, que en total correspondencia con los tratados internacionales firmados por México en materia de derechos humanos, el 12 de octubre de 2011 se publicó en el Diario Oficial de la Federación (DOF) un decreto de reforma al artículo 40. constitucional, elevando a rango constitucional el principio del interés superior de la niñez como elemento rector del diseño, ejecución, seguimiento y evaluación de las políticas públicas dirigidas a este grupo, el cual constituye un paso importante entre los progresos que ha alcanzado México para garantizar ascendentes niveles de bienestar para su población de niñas, niños y adolescentes.

Así también, en la misma fecha, se adiciona la fracción XXIX-P, al artículo 73 constitucional, respecto a las facultades del congreso, que textualmente dice:

Artículo 73... fracción XXIX-P. Expedir leyes que establezcan la concurrencia de la Federación, las entidades federativas, los Municipios y, en su caso, las demarcaciones territoriales de la Ciudad de México, en el ámbito de sus respectivas competencias, en materia de derechos de niñas, niños y adolescentes, velando en todo momento por el interés superior de los mismos y cumpliendo con los tratados internacionales de la materia de los que México sea parte.

Lo que "representa un gran avance para orientar la acción gubernamental hacia un enfoque de derechos, lo que se traduce en reconocer que los niños son titulares de derechos y no solo objeto de protección" (Cárdenas, 2016, p.42). 
LAS POLÍTICAS PÚBLICAS DE PROTECCIÓN INFANTIL: ADECUACIÓN AL INTERÉS SUPERIOR DEL NIÑO

Por consiguiente, el reconocimiento constitucional del interés superior del menor, como principio rector- guía, de las decisiones y actuaciones del Estado, implica la elevación al rango de los derechos fundamentales, este tema tratado en el área de derecho privado, matizando la importancia de "las normas constitucionales en todo el ordenamiento jurídico y por tanto, en el Derecho Civil se convierten así en decisivas, a tal extremo que la distinción tradicional entre Derecho Público y Privado, ha dejado de tener trascendencia"(Pérez Fuentes \& Cantoral Domínguez, 2015, pp.25-26), y es que es sostenible una aplicación perfeccionada puesto que al convertirse en un principio constitucionalmente reconocido, no solo están compelidos los órganos estatales, sino que paralelamente los particulares; o bien, la sociedad en su conjunto están constreñidos a cumplir con la disposición constitucional.

No se puede dejar de mencionar que la Convención sobre los Derechos del Niño posee un órgano de seguimiento de los compromisos adoptados por los países que la han ratificado: el Comité de los Derechos del Niño de la Organización de las Naciones Unidas, quien en sus observaciones finales sobre los informes periódicos cuarto y quinto combinados de México (2015) en su observación general número 19 sobre el interés superior del niño, exterioriza el acierto que ha tenido el Estado al reconocer constitucionalmente el derecho de los niños a que su interés superior sea una consideración primordial, no obstante la situación de los derechos del niño es más compleja en la realidad como se refleja al señalar el Comité que en la práctica no se ha respetado sistemáticamente este derecho.

El Comité recomienda al Estado parte que intensifique sus esfuerzos para que se integre adecuadamente este derecho y se aplique sistemáticamente "en todos los procedimientos y decisiones de índole legislativa, administrativa y judicial, así como en todas las políticas, programas y proyectos" que sean relevantes para los niños e incidan en ellos (Comité de los Derechos del Niño de la Organización de las Naciones Unidas, 2015, párr. 20).

El Comité acoge y destaca con satisfacción la adopción de la Ley General de los Derechos de Niñas, Niños y Adolescentes (LGDNNA, DOF, 2014), como medida legislativa que deroga a la ley anterior, además que entre los fines de la ley, inicialmente se reconoce a niñas, niños y adolescentes como titulares de derechos, y a su vez alienta al Estado, a elaborar procedimientos y criterios que sirvan de referencia a todas las personas competentes para determinar el interés superior del niño en todos los ámbitos y dar a ese interés el peso debido como consideración primordial. 
LAS POLÍTICAS PÚBLICAS DE PROTECCIÓN INFANTIL: ADECUACIÓN AL INTERÉS SUPERIOR DEL NIÑO

La ley primeramente da un enfoque garantista de Derechos Humanos, ya que "encontramos regulados dos principios que dirigirán todas las medidas, acciones y políticas públicas: el principio de la protección integral y el principio del interés superior del niño" (Pérez Contreras, 2013, p. 1152).

La ley está reconociendo a los niños como sujetos en la que sus necesidades se convierten en derecho, colocando el tema de la exigibilidad en un plano más amplio de modo que no se limita al plano jurídico, pues alcanza inclusive el plano político social de los derechos. Destaca un rediseño institucional al crear el Sistema Nacional de Protección Integral de los Derechos de Niñas, Niños y Adolescentes establecido en el artículo 125 de Ley General de los Derechos de Niñas, Niños y Adolescentes (LGDNNA): artículo 125, "Para asegurar una adecuada protección de los derechos de niñas, niños y adolescentes, se crea el Sistema Nacional de Protección Integral, como instancia encargada de establecer instrumentos, políticas, procedimientos, servicios y acciones de protección de los derechos de niñas, niños y adolescentes."

Es preciso señalar, que además de la consolidada estructura institucional que enmarca esta ley especial, a este tenor contempla la creación de una estrategia nacional, que "contendrá las políticas, objetivos, estrategias y líneas de acción prioritarias en materia de ejercicio, respeto, promoción y protección integral de niñas, niños y adolescentes" (Pérez Álvarez, 2015, p.300).

A fin de que, citando de nuevo a esta ley especial, es interesante observar como esta se encuentra integrada de un amplio catálogo de derechos humanos, incluyendo derechos civiles, sociales, culturales y económicos, excluyendo los derechos políticos, dada las propias y distintivas condiciones de los niños, como lo es la minoría de edad y la falta de formación de capacidades intelectuales necesarias; por lo demás es acorde a la Convención Americana sobre Derechos Humanos de 1969, en cuanto a definir sin discriminación alguna, a la persona como todo ser humano en su artículo $1^{\circ}$, y por ende, tratándose de menores tienen el mismo reconocimiento jurídico y social.

El objetivo de la ley en mención es garantizar el disfrute pleno y efectivo de todos los derechos reconocidos por la Convención y el "desarrollo holístico" del niño (Fondo de las Naciones Unidas para la Infancia [UNICEF], 2014, párr. 12) ${ }^{1}$.

\footnotetext{
${ }^{1}$ El Comité espera que los Estados interpreten el término "desarrollo" en su sentido más amplio, como concepto holístico que abarca el desarrollo físico, mental, espiritual, moral, psicológico y social del niño. Las medidas de LÓPEZ-MUÑOZZ. DEL C.
} 
LAS POLÍTICAS PÚBLICAS DE PROTECCIÓN INFANTIL: ADECUACIÓN AL INTERÉS SUPERIOR DEL NIÑO

Todos estos derechos previamente citados, no tienen "jerarquía entre sí, pues todos los derechos previstos responden al interés superior del niño y ningún derecho debería verse perjudicado por una interpretación negativa del interés superior del niño" (Comité de los derechos del niño, observación general número 14, 2013, párr. 4).

Es de precisarse que el sistema jurídico mexicano no se circunscribe únicamente a lo establecido en la Constitución Política de los Estados Unidos Mexicanos y en los tratados internacionales de los que el Estado mexicano forma parte, sino que también las leyes civiles, penales y del trabajo contribuyen y se han ido adecuando para garantizar el pleno ejercicio, respeto, protección y promoción de sus derechos en prominencia, es decir que también se ha favorecido el interés superior a través de diferentes medidas y no solo desde una óptica constitucional.

El sistema jurídico mexicano establece diversas prerrogativas de orden personal y social en favor de los menores, lo que se refleja tanto a nivel constitucional como en los tratados internacionales y en las leyes federales y locales, de donde deriva que el interés superior del menor implica que en todo momento las políticas, acciones y toma de decisiones vinculadas a esa etapa de la vida humana, se realicen de modo que, en primer término, se busque el beneficio directo del niño o niña a quien van dirigidos (Suprema Corte de Justicia de la Nación, 2011, p 2187)².

Con todo ello se hace necesario, indicar el contenido y función del interés superior del menor en los procesos de las políticas públicas, pues como ya ha quedado dicho, este concepto comprende de manera garantista la obligación y restricción hacia las autoridades, quienes, al adoptar medidas en afinidad a la población infantil, elegirán aquellas que reconozcan y resguarden sus derechos en sobremanera y no aquellas que puedan infringirlos inclusive por algún beneficio colectivo.

\section{Interés superior del niño: un principio rector}

El interés superior del menor es sin duda una cláusula de muchas dimensiones pero que irrefutablemente alude a todos los órganos o autoridades la obligación de que, ante cualquier medida o decisión, se debe evaluar los efectos que pudieran causar a este grupo social, y aunque

aplicación deben estar dirigidas a conseguir el desarrollo óptimo de todos los niños. Observaciones Generales del Comité de los Derechos del Niño, Observación general № 5.

2 Tesis I.5o. C. J/14, Novena Época, Tribunales Colegiados de Circuito, Semanario Judicial de la Federación y su Gaceta, Tomo XXXIII, marzo de 2011, p. 2187.

LÓPEZ-MUÑOZ Z. DEL C. 
LAS POLÍTICAS PÚBLICAS DE PROTECCIÓN INFANTIL: ADECUACIÓN AL INTERÉS SUPERIOR DEL NIÑO

la cuestión central no sean los derechos de la infancia, no se deberá dejar un vacío en su atención, ya que prevalecen sus necesidades.

En cuanto a su función en correlación a las políticas públicas, se considera, primeramente, que "todas las políticas públicas se asientan en una orientación normativa. Pero no en el sentido de la regulación, sino de los valores que se eligen para orientar la intervención del Estado: de lo que debe suceder; una orientación normativa en el sentido de la finalidad y las preferencias explicitas en las que se asientan. Esos valores pueden estar matizados o incluso condicionados por circunstancias insalvables, por modelos de selección previos o por ideologías definidas, pero, a final de cuentas, en ellas hay siempre una decisión normativa: valores más o menos explícitos que justifican los fines perseguidos (Merino, 2013, pp. 38-39).

Por consiguiente, al referirse el interés superior del menor como un criterio orientador de las políticas públicas, es de considerarse "la doctrina del Comité de los Derechos del Niño, en la que al ser estimado como uno de los principios de la Convención, estos no son sólo principios que informan el conjunto de derechos contenidos en la Convención, sino también de derechos autónomos, de forma que su no respeto en un caso concreto es una violación de los derechos del niño en sí mismo, sin necesidad de su vinculación con un derecho concreto de la Convención" (Cardona, 2012, p. 53).

Así pues, se sostiene por una parte la función justificativa y por otra la directiva, ya que este principio o disposición contempla un compuesto o conjunto de derechos, fundamentados en su reconocimiento y a su vez demanda de todos los órganos legislativos, judiciales y autoridades administrativas en general, sea considerado una regla o norma general que determine en todas las decisiones o medidas que realicen para satisfacer o disponer específicamente de las circunstancias o realidad de la que se hallen los menores.

Sobre el contenido o función que cumple el interés superior en nuestro ordenamiento jurídico, se ha pronunciado asimismo el Poder Judicial de la Federación en México (2016), en los siguientes términos:

El interés superior de los niños, niñas y adolescentes implica que el desarrollo de éstos y el ejercicio pleno de sus derechos deben ser considerados como criterios rectores para la elaboración de normas y la aplicación de éstas en todos los órdenes relativos a su vida. Así, todas las autoridades deben asegurar y garantizar que en todos los asuntos, decisiones y políticas LÓPEZ-MUÑOZZ. DEL C. 
LAS POLÍTICAS PÚBLICAS DE PROTECCIÓN INFANTIL: ADECUACIÓN AL INTERÉS SUPERIOR DEL NIÑO

públicas en las que se les involucre, todos los niños, niñas y adolescentes tengan el disfrute y goce de todos sus derechos humanos, especialmente de aquellos que permiten su óptimo desarrollo, esto es, los que aseguran la satisfacción de sus necesidades básicas como alimentación, vivienda, salud física y emocional, el vivir en familia con lazos afectivos, la educación y el sano esparcimiento, elementos -todos- esenciales para su desarrollo integral. En ese sentido, el principio del interés superior del menor de edad implica que la protección de sus derechos debe realizarse por parte de las autoridades a través de medidas reforzadas o agravadas en todos los ámbitos que estén relacionados directa o indirectamente con los niños, niñas y adolescentes, ya que sus intereses deben protegerse siempre con una mayor intensidad (Suprema Corte de Justicia de la Nación, 2016, p.10).

Es posible asumir, que en el proceso de las actuaciones de las autoridades públicas y políticas públicas en relación a la infancia, el reconocimiento jurídico que ha hecho el estado mexicano respecto al interés superior del menor, como un principio, demuestra que un primer momento se reconozca como objetivo socialmente valido, en el marco de una política pública, los derechos de los niños; pero ¿Por qué el interés superior del menor es un objetivo socialmente valido en el marco de una política?.

Los menores como grupo de personas, por sus características particulares, presentan conflicto de acceso o reunión de las condiciones óptimas de las medidas frecuentes de protección.

"La noción de infancia tiene un carácter histórico y cultural y es por ello que ha tenido diferentes apreciaciones en la historia; su concepción depende del contexto cultural de la época, sin embargo, en el movimiento de la modernidad se ha empezado a concebir la infancia como una categoría que encierra un mundo de experiencias y expectativas distintas a las del mundo adulto" (Jaramillo, 2007, pp. 110-112), en este escenario, todos los días la infancia atraviesa diferentes situaciones que ponen en riesgo su desarrollo y autonomía, en el ejercicio de sus derechos, y dichas situaciones se alteran aún más por las diferencias de edades y madurez de los niños, que requieren medidas o respuestas variadas, de ahí que son precisamente las que dan lugar a un trato especial, e inspiran la naturaleza principal del interés superior.

En este sentido, el contenido de las políticas, “justifica la movilización de los recursos del Estado para obtener resultados bien definidos; recursos que no necesariamente son monetarios, sino que también pueden ser regulaciones o medios de organización"(Merino, 2013, p.39); lo que conlleva a contrastar que la función del principio normativo del interés superior del menor, LÓPEZ-MUÑOZ Z. DEL C. 
LAS POLÍTICAS PÚBLICAS DE PROTECCIÓN INFANTIL: ADECUACIÓN AL INTERÉS SUPERIOR DEL NIÑO

intervenido por una autoridad investida de legitimidad y poder político, al tomar decisiones que envuelven los derechos en que se vean involucrados los niños, es en otras palabras su función justificativa, precisamente al evidenciar todos los derechos que tienen como objeto la protección y el reconocimiento del niño.

Tal como ha quedado señalado ya, en el pronunciamiento del Poder Judicial de la Federación, al exteriorizar que el principio del interés superior del menor de edad implica que desde el catálogo de derechos, dicho interés corresponde a la plena satisfacción de sus derechos, la función y contenido de ese interés son los propios derechos de los menores; el principio no alude solamente a un crecimiento físico saludable, pues este involucra el conglomerado de derechos que prevén el desarrollo emocional y psicológico del menor.

Por consiguiente, su protección debe realizarse por parte de las autoridades a través de medidas reforzadas o agravadas en todos los ámbitos que estén relacionados directa o indirectamente con los niños, niñas y adolescentes, ya que sus intereses deben protegerse siempre con una mayor intensidad.

Se deja claro que una política pública, no es una norma jurídica, dado que las políticas que se orientan en atención a los niños tienen la función de verificar y sustentar los derechos establecidos en la norma o instrumentos del sistema jurídico que responden al interés superior del niño como una consideración primordial a la que se atiende.

Por otra parte, en su función directiva, se desprende el carácter del interés superior del menor que asume como criterio rector y limitante de las decisiones de las autoridades, indistintamente del cual sea su naturaleza, en consecuencia, su protección efectiva depende en gran manera del conjunto de medidas y mecanismos que integran las políticas públicas.

En los procesos de toma de decisiones para dar respuesta a problemas públicos específicos, en primer término, deben considerarse criterios que accedan a lograr los objetivos que se persiguen, ciertamente son muchos los problemas que aquejan a la sociedad, pero la posibilidad de que alguno sea atendido por el Estado requiere que transite por una directriz.

En efecto, el interés superior del niño debe ser el factor determinante al tomar una decisión relacionada con la adopción, pero también relacionadas con otras cuestiones (Comité de los derechos del niño, observación general número 14, 2013, párr. 38), pues en el diseño de políticas 
LAS POLÍTICAS PÚBLICAS DE PROTECCIÓN INFANTIL: ADECUACIÓN AL INTERÉS SUPERIOR DEL NIÑO

públicas eficientes y viables, además de identificar a la población infantil como actores involucrados, se debe desarrollar la mejor estrategia para ellos, considerando lo que sea mejor para el niño.

Como hipótesis puede entonces proponerse, que los contenidos de dos políticas públicas pudieran corresponder perfectamente a uno los derechos de los niños establecido en normas nacionales e internacionales, sin embargo, nada garantiza que ambas tengan un mismo nivel de protección, pues es una realidad que la política pública debe pasar un proceso de diferentes filtros que implican su análisis y discusión, utilizando diversos parámetros, valores, intereses y visiones.

La aplicación del interés superior como criterio orientador es la que analiza y sopesa las medidas que sean más pertinentes. Tal como lo mencionó el Comité de los Derechos del Niño, en su observación general número 5 , párrafo 45 , pues exterioriza que al formular políticas en todos los niveles de los poderes públicos se requiere un proceso continuo de valoración de los efectos sobre los derechos del niño, a fin de prever las consecuencias de cualquier propuesta de política o asignación presupuestaria en los niños y el disfrute de sus derechos, y de evaluación de los efectos sobre los derechos del niño, con miras a juzgar las consecuencias reales de la aplicación.

En suma, el interés superior del niño, como criterio rector u orientador no apunta solamente a la producción normativa y la interpretación o aplicación del derecho por parte del poder judicial, pues además sitúa a las medidas, políticas públicas, acciones y programas definidos que integran la agenda pública.

Sin embargo, al connotar el interés superior del menor como principio constitucional, es preciso observar que su contenido no es primordial a una institución que beneficie a la infancia en su integridad, seguridad física y emocional, pues del mismo modo los niños al ser portadores de derechos y vulnerables por sus particularidades, se atribuyen a las entidades administrativas acoger las medidas necesarias para garantizar el bienestar de dichos menores, previendo una disociación que impida cualquier peligro que origine daños a su persona y derechos.

En materia de la obligación de todas las autoridades federales y locales de coordinar la implementación y ejecución de las acciones y políticas públicas, esta presenta modalidades especiales y extensas en relación con los menores. 
LAS POLÍTICAS PÚBLICAS DE PROTECCIÓN INFANTIL: ADECUACIÓN AL INTERÉS SUPERIOR DEL NIÑO

Asimismo, el Comité de los Derechos del Niño, en la multicitada observación general número 14 (2014): pone de relieve que el alcance de las decisiones tomadas por las autoridades administrativas a todos los niveles es muy amplio y abarca, entre otras, las decisiones relativas a la educación, el cuidado, la salud, el medio ambiente, las condiciones de vida, la protección, el asilo, la inmigración y el acceso a la nacionalidad. Las decisiones particulares adoptadas por las autoridades administrativas en esas esferas deben ser evaluadas en función del interés superior del niño y han de estar guiadas por él, al igual que todas las medidas de aplicación (Fondo de las Naciones Unidas para la Infancia [UNICEF], 2014, párr. 30).

En definitiva, su función directiva encuentra su fundamento como ya se mencionó, en la reforma al artículo $4^{\circ}$ en la Constitución Política de los Estados Unidos Mexicanos, se eleva no solo como un derecho fundamental indicado de manera explícita en el derecho mexicano, sino además al reconocerse como un principio, impone obligación a la autoridad, de adecuarlo a cualquier medida que se tome, pues el principio deberá guiar el diseño, ejecución, seguimiento y evaluación de las políticas públicas dirigidas a la niñez.

\section{CONCLUSIONES}

El interés superior del menor, es en principio polifacético y dinámico ya que se va ajustando a las necesidades de los menores para que estos estén en preminencia, y en su carácter de principio rector de las políticas públicas, desempeña una función justificativa y directiva, debido a que esta disposición contempla un conglomerado de derechos, fundamentados en su reconocimiento y a su vez respectivamente demanda de todos los órganos legislativos, judiciales, autoridades administrativas en general, que sea considerado un criterio orientador determinado en todas las decisiones o medidas que realicen para satisfacer o disponer específicamente de la circunstancia o realidad de la que se halle el menor.

En definitiva, "constituyen un conjunto de derechos-garantía frente a la acción del Estado y representan, por su parte, un deber de los poderes públicos de concurrir a la satisfacción de los derechos-prestación" (Torres Zarate \& García Martínez, 2007, p.105).

Puede afirmarse que "la cláusula del interés superior del niño introduce un criterio finalista de maximización de los derechos" (Garrido, 2013, p.143), así que en la consolidación de las políticas públicas en materia de protección de la infancia es indefectible que cabalmente las acciones respeten y estén bajo un sistema de derechos, de los cuales los niños son titulares y además LÓPEZ-MUÑOZ Z. DEL C. 
LAS POLÍTICAS PÚBLICAS DE PROTECCIÓN INFANTIL: ADECUACIÓN AL INTERÉS SUPERIOR DEL NIÑO

consientan el respeto a su dignidad en un contexto del que es necesario que sus derechos sean una realidad.

Se sostiene de manera reiterada el párrafo noveno del artículo 4 de la Constitución Política de los Estados Unidos Mexicanos (CPEUM), el cual a la letra dice: En todas las decisiones y actuaciones del Estado se velará y cumplirá con el principio del interés superior de la niñez, garantizando de manera plena sus derechos. Los niños y las niñas tienen derecho a la satisfacción de sus necesidades de alimentación, salud, educación y sano esparcimiento para su desarrollo integral. Este principio deberá guiar el diseño, ejecución, seguimiento y evaluación de las políticas públicas dirigidas a la niñez (art.4, parr.9).

En el se establece visiblemente el carácter del interés superior del menor como principio que por una parte asegura de forma íntegra todos los derechos de los cuales son titulares la población infantil y por otra parte, paralelamente a ese contenido, se indica su función como criterio orientador al ser establecido como guía en el proceso de las políticas públicas del estado mexicano.

\section{REFERENCIAS BIBLIOGRÁFICAS}

Cárdenas Miranda, E. (2016). La situación de la infancia y la adolescencia en México. En González Martín, Nuria y Rodríguez Jiménez, Sonia, et. al., (coords.), Temas selectos de vulnerabilidad y violencia contra niños, niñas y adolescentes, México: UNAM, Instituto de Investigaciones jurídicas.

Cardona Llorens, J. (2012). La Convención sobre los Derechos del Niño: significado, alcance y nuevos retos. Educatio Siglo XXI ,30(2), 47-67.

Comité de los Derechos del Niño de la Organización de las Naciones Unidas. (2015). Observaciones finales sobre los informes periódicos cuarto y quinto combinados de México, aprobadas en la sesión 2024 de 5 de junio de 2015. Recuperado de http://www.unicef.org/mexico/spanish/CRC_C_MEX_CO_4-5.pdf

Comité de los Derechos del Niño. (2013). Observación General numero 14 sobre el derecho del niño a que su interés superior sea una consideración primordial. Recuperado de http://www.unicef.cl/web/informes/derechos_nino/14.pdf 
LAS POLÍTICAS PÚBLICAS DE PROTECCIÓN INFANTIL: ADECUACIÓN AL INTERÉS SUPERIOR DEL NIÑO

Constitución Política de los Estados Unidos Mexicanos. (1917). Última reforma publicada el 27 de agosto de 2018.2 Recuperado de http://www.diputados.gob.mx/LeyesBiblio/pdf/1_270818.pdf

Dueñas Moncada, N. (2016). Vulnerabilidad y violencia contra niños, niñas y adolescentes: marco teórico conceptual. En N. González Martín y S. Rodríguez Jiménez, Sonia, et. al., (coords.), Vulnerabilidad y violencia contra niños, niñas y adolescentes: marco teórico conceptual, México: UNAM, Instituto de Investigaciones jurídicas.

Franco Corzo, J. (2017). Diseño de políticas públicas. Una guía práctica para transformar ideas en proyectos viables, México: IEXE.

Garrido Álvarez, R. (2013). El interés superior del niño y el razonamiento jurídico, problema. Anuario de filosofía y teoría del derecho, (7), pp. 115-147.

Jaramillo, L. (2007) Concepciones de infancia, Zona Próxima (8), pp. 108-123.

Ley General de los Derechos de Niñas, Niños y Adolescentes, Diario Oficial de la Federación. (4 de diciembre 2014). Publicada en el Diario Oficial de la Federación.

López-Contreras, R. (2015). Interés superior de los niños y niñas: Definición y contenido, Revista Latinoamericana de Ciencias Sociales, Niñez y Juventud, 13(1), pp. 51-70.

Suprema Corte de Justicia de la Nación, Pleno. (septiembre de 2016). Semanario Judicial de la Federación y su Gaceta. Jurisprudencia Constitucional P./J. 7/2016 (10a.), Decima Época, tomo I, p.10.

Suprema Corte de Justicia de la Nación, (marzo de 2011). Semanario Judicial de la Federación y su Gacet. Tesis I.5o. C. J/14, (9a.), Novena Época, Tomo XXXIII, p.2187.

Merino, M. (2013). Políticas públicas. Ensayo sobre la intervención del Estado en la solución de problemas públicos, México: CIDE.

Merino, M. y Cejudo, G. (2010). Problemas, decisiones y soluciones: Enfoques de políticas públicas. México: CIDE-FCE.

Pérez Álvarez, F. (2015). Comentario a la Ley General de los Derechos de Niñas, Niños y Adolescentes, Revista Mexicana de Derecho Constitucional, UNAM-Instituto de Investigaciones Jurídicas, (32), pp. 295-302.

Pérez Contreras, M. (2013). El entorno familiar y los derechos de las niñas, los niños y los adolescentes: una aproximación, Boletín Mexicano de Derecho Comparado, (138), pp. 1151-1168. 
LAS POLÍTICAS PÚBLICAS DE PROTECCIÓN INFANTIL: ADECUACIÓN AL INTERÉS SUPERIOR DEL NIÑO

Pérez Fuentes, G. y Cantoral Domínguez, K. (2015). Daño moral y derechos de la personalidad del menor. México: Tirant Lo Blanch.

Sandoval Vásquez, A. (2011). Derechos humanos y políticas públicas. Reflexiones, 90(2), 101114.

Torres Zárate, F. y García Martínez, F. (2007). El interés superior del niño en la perspectiva del garantismo jurídico en México, Alegatos, (65), pp. 97-112.

UNICEF (Fondo de las Naciones Unidas para la Infancia). (2014). Observaciones Generales del Comité de los Derechos del Niño. Recuperado de https://www.unicef.org/ecuador/UNICEFObservacionesGeneralesDelComiteDeLosDerechosDelNino-WEB.pdf

Valentin Mballa, L. (2017). Políticas públicas y complejidad: en búsqueda de soluciones a los problemas públicos, México, MaPorrúa. 